\title{
Data sharing: A new editorial initiative of the International Committee of Medical Journal Editors
}

\author{
Implications for the Editors' Network
}

\author{
F. Alfonso ${ }^{1}$
}

Published online: 3 April 2017

(C) The Author(s) 2017. This article is available at SpringerLink with Open Access.

\begin{abstract}
The International Committee of Medical Journal Editors (ICMJE) provides recommendations to improve the editorial standards and scientific quality of biomedical journals. These recommendations range from uniform technical requirements to more complex and elusive editorial issues including ethical aspects of the scientific process. Recently, registration of clinical trials, conflicts of interest disclosure, and new criteria for authorship - emphasising the importance of responsibility and accountability - have been proposed. Last year, a new editorial initiative to foster sharing of clinical trial data was launched. This review discusses this novel initiative with the aim of increasing awareness among readers, investigators, authors and editors belonging to the Editors' Network of the European Society of Cardiology.
\end{abstract}

Keywords Editorial ethics - Scientific process - Data sharing - Clinical trial - Trial registration - Authorship · Conflict of interest $\cdot$ Big-data $\cdot$ Scientific journals

This is a joint simultaneous publication initiative involving all interested National and Affiliated Cardiovascular Journals of the European Society of Cardiology.

F. Alfonso is Chairman of Editors' Network. On behalf of the Editors' Network European Society of Cardiology Task Force; see Appendix for affiliations.

F. Alfonso

falf@hotmail.com

1 Department of Cardiology, Hospital Universitario de La Princesa, Instituto de Investigación Sanitaria IIS-IP, Universidad Autónoma de Madrid, Madrid, Spain
The Editors' Network of the European Society of Cardiology (ESC) is committed to promoting the implementation of high-quality editorial standards among ESC National Societies Cardiovascular Journals (NSCJ) [1-4]. NSCJ play a major role in disseminating high-quality scientific research. However, they also play a relevant role in education and harmonisation of clinical practice [3]. Most NSCJ are published in local languages, but many have English editions and have gained international scientific recognition [1-4]. NSCJ complement well the official ESC journals and, altogether, provide an effective means to disseminate European cardiovascular research. In a globalised and highly competitive editorial environment, promoting high-quality editorial standards remains of paramount importance to increase the scientific prestige of NSCJ [1-4]. From its conception, the Editors' Network strongly advocated for adherence to the uniform recommendations of the International Committee of Medical Journal Editors (ICMJE) [1]. In its mission statement document the Editors' Network committed to adapt NSCJ to follow these general editorial recommendations [1]. However, NSCJ are highly heterogeneous in scope and contents and these new recommendations should be embraced progressively, considering currently existing editorial policies and the editorial freedom of the NSCJ [1-4].

Ethical issues play a growing role in ensuring the credibility of the scientific process [5-13]. Biomedical research relies on trust. However, transparency also represents a major tenet in the scientific process [5-8]. This review will discuss the new editorial recommendations on data sharing issued by the ICMJE [14]. Novel ICMJE recommendations always appear as provocative, and often as too ambitious, when initially presented. Moreover, implementation of editorial changes is rather demanding from a technical and logistical viewpoint. Adherence to novel editorial initia- 
tives is challenging not only for editors, but also for the entire scientific community. Therefore, many editors have a natural tendency to avoid stepping ahead as early adopters of new 'editorial experiments' and usually prefer to keep moving within their comfort zone until the 'sea change' has matured [1-4]. However, experience has taught us that all editorial initiatives developed by the ICMJE eventually prevailed and played a critical role in maintaining the credibility of the scientific process [9-13]. Highly successful recent examples include trial registration, a conflicts of interest initiative and the new requirements for authorship [9-13].

The novel ICMJE recommendations on data sharing [14] are discussed herein from a didactic perspective with the aim to provide new editorial insights and, hopefully, to be progressively adopted and implemented by the NSCJ.

\section{Sharing clinical trial data: The new ICMJE proposal}

The ICMJE considers that there is a moral obligation to responsibly share the data generated by clinical trials [14]. The rationale underlying this global endeavour is that patients have assumed a risk by accepting to participate in a trial. Accordingly, making the obtained data publicly available represents a responsible initiative to facilitate the advancement of science. Sharing the data would increase trust in the conclusions reached by trials. Indeed, data sharing allows confirmation of the results by independent research [14]. Furthermore, new hypotheses may be pursued by different groups of investigators. This initiative may foster the leveraging of data to answer different research questions not contemplated in the original study. If science becomes an open process, then many researchers would benefit by taking advantage of reliable data generated somewhere else. Therefore, data sharing emerges as the best way to ensure that all the information gathered by trials is made freely and widely available, so that it can be readily used to advance scientific knowledge [14]. The use of previously collected data to further advance science is difficult to criticise. As discussed, this honours the volunteerism of the patients who signed up and consented to participate in a trial.

Governments, funding agencies, scientific societies, the industry and even the lay society growingly demand sharing clinical trial data. Therefore, the ICMJE suggests that editors should help to meet this ethical obligation by devising new editorial policies specifically addressing this issue [14]. Proponents of 'open science' should be pleased by this new editorial requirement of sharing clinical trial data [14].
The first consideration is to clarify what a clinical trial is exactly. According to the ICMJE definition, a clinical trial is a study that prospectively assigns people to an intervention in order to assess the cause-and-effect relationship between that intervention and the ensuing health outcome [5].

The ICMJE considers that sharing 'de-identified' individual patient data should become part of the publication process of clinical trials [14]. This strategy protects patient's confidentiality rights. The requirement, however, is restricted to the individual-patient data underpinning the results presented in the published article. Importantly, a clear plan for data sharing should be disclosed at the time of initial trial registration and should be also presented at the time of manuscript submission. The proposal requires clinical trialists to declare that they will share their data publically as a prerequisite for publishing the trial [14]. They should promise to freely release individual patient raw data at the time they submit the manuscript for consideration.

It is important to keep in mind that clinical trial registration was a previous ICMJE editorial initiative aimed to address problems related to publication bias (selective publication of positive trials), endpoints inconsistency and redundant research $[9,10]$. Potentially, public repositories provide an optimal tool not only for initial trial registration but also for individual-patient data sharing. From now on the plan for data sharing would be an important step of the clinical trial registration initiative [9, 10, 14]. Details on whether the data would be freely available upon request, or only after a formal application that eventually will be approved after an agreement is reached on data use conditions, should be presented. Finally, it has been proposed that the data should be made public no more than 6 months after publication of the original study in the journal $[9,10,14]$. Clinicaltrials.com, a widely used non-for profit scientific repository $[9,10]$, has already adapted its registration platform to specifically clarify data-sharing plans at the time of clinical trial registration.

Obviously, this editorial initiative may have profound consequences on the planning, conduction and reporting of clinical trials and, in fact, may deeply influence research and publication strategies [14]. As a result, the idea is to implement this requirement for any clinical trial that begins to enrol patients 1 year after the official adoption of this editorial policy by the corresponding journal [14]. The initiative will also have major implications for the editorial process. Indeed, editors are supposed to monitor the datasharing process and, eventually, address potential irregularities. These might include requests of clarification to the authors, notification to academic institutions, publication of expressions of concern or even retractions.

Finally, the ICJME acknowledges that the rights of the investigators and sponsors should be protected [14]. Moreover, credit to the original report should be granted by in- 
cluding a unique identifier of the dataset. It is emphasised that credit should be always given to the original investigators that posted the data after publication of their research. Furthermore, additional investigators using these databases should request collaboration of the investigators that originally collected the data to ensure adequate data interpretation, management and analysis.

\section{Challenges of data sharing}

Although it appears clear that this initiative will further improve transparency and the overall integrity of the scientific literature, some remaining issues need to be addressed. There is inherent resistance to embrace open science initiatives from some academic institutions or investigators that defend the idea of exploiting their 'own' data $[15,16]$. Until now clinical researchers were discouraged from working with clinical trial data they did not generate themselves $[15,16]$. Likewise, trialists tended to see trial data as their personal property and would routinely refuse requests for data sharing. In fact, until very recently most researchers and pharmaceutical industry groups were opposed to making raw data available after trial publication. This practice, however, differs from other disciplines (such as genomics or economics) where data sharing has been common place for a long time $[15,16]$.

Obtaining reliable, high-quality original data requires a major research effort. Allowing a sufficient period of time from the time of article publication to the need to share the raw data would give original investigators the possibility of publishing additional subgroup analyses from their own data [14]. This new proposal will further increase the pressure on academic investigators that frequently do not have the required resources to publish their subsequent analyses and require time to prepare the new manuscripts [14]. Notably, most researchers have no experience with the process of releasing or dealing with public data. Furthermore, the effort and resources required to organise the raw data in a way that would be comprehensible to other investigators remain a cause of major concern [14]. This would require technical support and adequate funding.

Data access to non-trial researchers may disclose problems not recognised by the initial investigators. Although this will increase transparency and, therefore, trust in trial results, it might also generate confusion and undue scientific controversies. It is difficult to envision how the new researchers will gain the required detailed knowledge of the complicated datasets enjoyed by the original trial investigators [14]. A reliable assessment of the data requires a deep knowledge on the study background and to be able to properly address many nuances and practical considerations. These include precise information on the way vari- ables were defined, how data was collected and how results were finally coded and entered into the database. The initiative might be fraught with problems related to incorrect analysis resulting in inaccurate results and erroneous interpretations, potentially damaging science [14].

Finally, editors, already deluged with work, will need to check that all of the raw data of the published articles have eventually been released as promised. Different results may emerge from misconceptions regarding what data should be analysed to answer specific questions [14]. If there are differences in results, it will be difficult to decide which analysis provides the most accurate reflection of the data. This could generate undue 'scientific noise', with contradictory results and rectifications, which may generate confusion and frustration in the scientific community. Finally, this may also promote the simultaneous publication in several journals of conflicting results from the same database by different groups [14].

As many issues should still be clarified, the ICMJE asked for feedback on its preliminary editorial proposal on clinical trial data sharing [14]. Obviously, the initiative will only gain the required maturity from the experience gained during its adoption and implementation.

\section{Previous initiatives on data sharing}

Several leading academic entities have previously worked in this field. The British Medical Journal pioneered an editorial initiative of data sharing [17]. In 2012 this policy took effect only for trials on drugs and devices but, in 2015, the requirement of data sharing 'on request' was extended to all submitted clinical trials [17]. It has been proposed that individual patient data may also be of major value during the 'peer review' process by permitting independent verification of the results before final publication [18]. Although this initiative might be of potential value most reviewers are already deluged with work and this extra task could generate fatigue and burn out phenomena. In addition, many good clinical reviewers do not have the expertise required to manage data and to perform confirmatory statistical analyses [18]. Some journals, such as JAMA, previously developed some related editorial initiatives including the request for independent statistical analyses by an academic statistician of industry-sponsored trials [19].

The World Health Organisation (WHO) and the Institute of Medicine (IOM) previously made important declarations on clinical trial transparency. In this regard, the IOM issued specific guidelines for trial data sharing [20]. WHO initially presented a statement on public disclosure of clinical trial results and, subsequently, encouraged sharing of research datasets whenever appropriate [21-23]. More recently, the WHO developed global norms for sharing data 
and results during public health emergencies, with special focus on clinical, epidemiological, and genetic features of new infectious diseases and experimental therapeutics and vaccines. In emergency situations, data need to be shared quickly before the information is formally published [23].

Finally, the National Health, Lung and Blood Institute (NHLBI) presented detailed data-sharing practices allowing public access to trial raw data and developed a data repository currently including over half a million patients from over 100 trials and observational studies [24]. In 2015 the NHLBI discussed its intent to make public the digital data from its funded trials [24].

\section{Platforms and repositories}

Up to 30,000 clinical trials are conducted annually worldwide generating a huge volume of patient-level raw data [25]. Currently, however, available portals for data sharing are still not adequate. Most of them require a time-consuming request, including a detailed research proposal with the study design, main endpoints and a statistical plan [25]. The submitted proposal is then reviewed by an independent research panel that decides whether to approve the request for data $[21,25,26]$. Currently, this process takes too long and when the data are eventually obtained oftentimes they are not readily usable [25]. However, the means to facilitate data sharing from the data holder to the researcher may be cumbersome and challenging to implement. Some systems provide an electronic form or template [21]. Nevertheless, when these are not available a 'de novo' proposal should be generated outlining the purpose, the statistical analysis plan, the research team, and potential conflicts of interest. The review process may come from an internal or external review panel selected by the data holder or by a third party [25-27]. Finally, data can be shared through a public website or by direct communication between the data holder and the researcher. In most cases, however, controlled access is required. Before any analysis is started reviewing all the accompanying documentation to assist the researcher in the understanding of the original clinical trial and the methodology used, remains critical. Furthermore, the data holder may require a legally binding data-sharing agreement and should be available to provide the required support should questions arise [27].

Major care should be taken to prevent the perils that may undermine the value of data sharing [14]. Data from trials should be responsibly used [28]. A recent survey from UK Clinical Trial Units disclosed some potential risks associated with data sharing [29]. These basically included a) misuse of data, b) incorrect secondary analyses, c) resource requirements and d) identification of patients [29, 30]. Researchers are responsible for presenting the data in a format amenable for external secondary use. Repositories should be prepared to make raw data available in standardised platforms in a fully comprehensive manner. Data sharing from trials with anonymised patient-level data with associated metadata and supporting information should be made available to other researchers following an independent analysis of the research proposals. Developing and adopting standard approaches to protecting patient privacy are urgently required [14]. Finally, an adequate infrastructure should be organised to support effective data sharing. In this regard, the role of the industry is significantly growing as demonstrated by some joint initiatives, such as the Yale University Open Data (YODA) project [16, 31].

Some academic research organisation consortiums particularly focussed on the study of cardiovascular diseases [32] have developed interesting tools for data sharing. This cardiovascular initiative requires presentation of a standardised request in a Web portal. Proposals are to be analysed by a scientific committee, including members designated by the consortium and a statistician along with the trial's principal investigator. The idea is to ensure an adequate use of the database and correct statistical analyses, while averting the problem of multiple investigators proposing the same analyses [32].

\section{Statistical issues}

Statisticians play a key role in developing data-sharing strategies [19]. They should be involved from the very beginning to organise the research strategy and the required analytical techniques [19]. In this scenario statisticians should move from their classical role as data 'gatekeepers' to that of data 'facilitators' [19]. A data-sharing working group of medical research statisticians has recently been created from the pharmaceutical and biotechnological industry and from academia. The idea was to address the technical and statistical challenges of accessing research data for re-analyses. Specific techniques are required to ensure adequate data manipulation to convert the data initially collected and entered in the data base into data that is analytically usable. Converting raw data into standardised formats may be challenging. Moreover, familiarity with the required statistical programing language is necessary. Independent statisticians should play a major role in guiding the principles of re-analysis based on the researchers' request while, at the same time, guarding against misleading conclusions. They should be fully aware that additional analysis may yield different results compared with the original analyses. Accordingly, they should be prepared to face criticism but, at the same time, they should be able to openly challenge previous statistical methods [19]. 
Statistical guidance may be required for appropriate interpretation of results from re-analyses where different methods have been utilised. In particular, it is important to keep in mind the inherent risk of over-interpretation of the results from multiple subgroup analyses [33]. Likewise, documents for best practices in data anonymisation have been developed [34]. Statisticians should also be familiar with this methodology. Risk to patient privacy can be mitigated by data reduction techniques. Data holders are responsible for generating de-identified datasets to offer protection for patient privacy through masking or generalisation of main identifiers. In addition, legally binding data-sharing agreements should include a compromise not to attempt to identify patients [34]. In particular, it is recommended that data use agreements are signed by the data holder and researchers. Only appropriately qualified 'named' researchers should be granted access to the data. Finally, high security levels should be implemented for data transferring. Resources, costs and effort required to make patient-level data available for third party research may be considerable and, therefore, adequate funding should be organised [34].

\section{Credit to the original authors}

A clear motivation for researchers to conduct randomised clinical trials is the opportunity to publish different studies in addition to the main manuscript with the primary endpoint. These secondary analyses may be of major value to unravel new findings from the original dataset $[35,36]$. Many have proposed that the time to open the process of data sharing should be extended to 2 years, or even to 5 years in selected complex or large studies. This will allow precious time for the original investigators to further scrutinise and analyse in depth their own data. As blinding is necessary during trial execution, once the study is completed the research teams concentrate on publishing the primary findings as soon as possible. Following this, there is usually a series of pre-planned additional analyses. These studies are organised by collaborative research teams from different institutions, but usually with relatively poor support. Secondary analyses are also very important for co-investigators and junior scientists. To respect this legitimate interest an extension from the 6-month period after the primary data have been published has been advocated $[35,36]$.

Academia rewards scientists with recognition for making their discoveries public. Credit should be granted to the original researchers that create datasets which other investigators find useful $[14,15]$. Otherwise, original investigators may be tempted to consider those performing secondary analyses of their data as 'research parasites'. Furthermore, mechanisms are required to ensure that the external analy- ses are conducted adequately and not merely to undermine the original findings. Direct collaboration between primary and secondary researchers is, therefore, necessary to ensure proper data analysis and interpretation [14, 15]. The original investigators who designed and conducted the trial and obtained sources of funding deserve to receive adequate scientific credit [28].

\section{Conclusions}

The data transparency revolution is here to stay. This is just another step ahead into a culture of 'open science' and it is clear that we are at the dawn of a new age $[37,38]$. Several European National Societies have already developed registry programs in which the registry databases are public for the use of their members [39]. Major challenges and hurdles in the adoption and implementation of the new ICMJE recommendation should still be overcome [40]. Experience gained by leading journals will eventually allow a balanced compromise between the interests of the original researchers and that of the scientific community as a whole. NSCJ should progressively adapt their policies to increase awareness of the importance of data sharing and promote policies designed to enhance transparency in biomedical research.

Acknowledgements We are grateful for the support and assistance of Ismahen Ouertani and Michael Alexander from the ESC Publications Department at the European Heart House.

Conflict of interest F. Alfonso and none of the editors or authors of this paper has any potential conflict of interest that needs to be disclosed in relation to this manuscript.

Open Access This article is distributed under the terms of the Creative Commons Attribution 4.0 International License (http:// creativecommons.org/licenses/by/4.0/), which permits unrestricted use, distribution, and reproduction in any medium, provided you give appropriate credit to the original author(s) and the source, provide a link to the Creative Commons license, and indicate if changes were made.

\section{Appendix}

Editors in Chief (in alphabetical order) and their journals

\begin{tabular}{ll}
\hline Editor in Chief & National Society Journal \\
\hline $\begin{array}{l}\text { Karlen Adamyan } \\
\text { Jean-Yves Artigou }\end{array}$ & $\begin{array}{l}\text { Armenian Journal of Cardiology } \\
\text { Archives des maladies du cœur et des vais- } \\
\text { seaux-Pratique } \\
\text { Cor et Vasa }\end{array}$ \\
$\begin{array}{l}\text { Michael Ascher- } \\
\text { mann }\end{array}$ & Clinical Research in Cardiology \\
\hline
\end{tabular}




\begin{tabular}{|c|c|}
\hline Editor in Chief & National Society Journal \\
\hline Alfonso Buendia & Archivos de Cardiologia de Mexico \\
\hline Pao-Hsien Chu & Acta Cardiologica Sinica \\
\hline Ariel Cohen & Archives of Cardiovascular Diseases \\
\hline Mirza Diliç & Medicinski Zurnal \\
\hline Anton Doubell & SA Heart \\
\hline Dario Echeverri & Revista Colombiana de Cardiologia \\
\hline Nuray Enç & Kardiyovaskuler Hemsirelik Dergisi \\
\hline $\begin{array}{l}\text { Ignacio Ferreira- } \\
\text { González }\end{array}$ & Revista Española de Cardiología \\
\hline Krzysztof J. Filipiak & Kardiologia Polska \\
\hline Andreas Flammer & Cardiovascular Medicine \\
\hline Eckart Fleck & Cardio News \\
\hline Plamen Gatzov & Bulgarian Journal of Cardiology \\
\hline Carmen Ginghina & Romanian Journal of Cardiology \\
\hline Lino Goncalves & Revista Portuguesa de Cardiologia \\
\hline Habib Haouala & Cardiologie Tunisienne \\
\hline $\begin{array}{l}\text { Mahmoud Has- } \\
\text { sanein }\end{array}$ & The Egyptian Heart Journal \\
\hline Gerd Heusch & Basic Research in Cardiology \\
\hline Kurt Huber & Austrian Journal of Cardiology \\
\hline Ivan Hulín & Cardiology Letters \\
\hline Mario Ivanusa & Cardiologia Croatica \\
\hline $\begin{array}{l}\text { Rungroj Krit- } \\
\text { tayaphong }\end{array}$ & Thai Heart Journal \\
\hline Chu-Pak Lau & $\begin{array}{l}\text { Journal of the Hong Kong College of Cardi- } \\
\text { ology }\end{array}$ \\
\hline François Mach & Cardiovascular Medicine \\
\hline $\begin{array}{l}\text { Germanas Marin- } \\
\text { skis }\end{array}$ & Chief Seminars in Cardiovascular Medicine \\
\hline Livio Dei Cas & Journal of Cardiovascular Medicine \\
\hline Luiz Felipe Moreira & Arquivos Brasileiros de Cardiologia \\
\hline Tuomo Nieminen & Sydänääni (Heart Beat) \\
\hline Latifa Oukerraj & La Revue Marocaine de Cardiologie \\
\hline Stefan Perings & Der Kardiologie \\
\hline Jan Piek & Netherlands Heart Journal \\
\hline Luc Pierard & Acta Cardiologica \\
\hline Tatjana Potpara & Heart and Blood Vessels \\
\hline $\begin{array}{l}\text { Walter Reyes- } \\
\text { Caorsi }\end{array}$ & Revista Uruguaya de Cardiologia \\
\hline Se-Joong Rim & Korean Circulation Journal \\
\hline Olaf Rødevand & Hjerteforum \\
\hline Georges Saade & Heart News \\
\hline Mikael Sander & Cardiologisk Forum \\
\hline Evgeny Shlyakhto & Russian Journal of Cardiology \\
\hline Bilgin Timuralp & Anatolian Journal of Cardiology \\
\hline Dimitris Tousoulis & Hellenic Journal of Cardiology \\
\hline Dilek Ural & $\begin{array}{l}\text { Archives of the Turkish Society of Cardiol- } \\
\text { ogy }\end{array}$ \\
\hline Albert Varga & Cardiologia Hungarica \\
\hline Thomas F. Lüscher & European Heart Journal \\
\hline
\end{tabular}

\section{References}

1. Alfonso F, Ambrosio G, Pinto FJ, et al. European national society cardiovascular journals. Background, rationale and mission statement of the 'editors' club. Rev Esp Cardiol. 2008;61:644-50.

2. Network ESC task force. European society of cardiology national cardiovascular journals: the 'editors' network. Eur Heart J. 2010;31:26-8.

3. Mills P, Timmis A, Huber K, et al. The role of European national journals in education. Heart. 2009;95:e3.

4. Alfonso F. The editors' network of the european society of cardiology. Eur Heart J. 2011;32:919-21.

5. International Committee of Medical Journals Editors. Recommendations for the Conduct, Reporting, Editing, and Publication of Scholarly Work in Medical Journals. Updated December 2015. http://www.icmje.org.

6. Council of Science Editors. White paper on publication ethics. CSE's white paper on promoting integrity in scientific journal publications 2012. http://www.CouncilScienceEditors.org..

7. World Association of Medical Editors. WAME Professionalism Code of Conduct The new WAME Professionalism Code of Conduct for medical journal editors. http://www.wame.org.

8. Committee On Publication Ethics (COPE). Code of Conduct and Best Practice Guidelines for Journal Editors. http://publicationethics. $\mathrm{org} / \mathrm{resources} /$ guidelines.

9. International Committee of Medical Journal Editors, De Angelis $\mathrm{CD}$, Drazen JM, Frizelle FA, et al. Is this clinical trial fully registered? - A statement from the International Committee of Medical Journal Editors. N Engl J Med. 2005;352:2436-8.

10. Alfonso F, Segovia J, Heras M, Bermejo J. Publication of clinical trials in scientific journals: editorial issues. Rev Esp Cardiol. 2006;59:1206-14.

11. Drazen JM, Van der Weyden MB, Sahni P, et al. Uniform format for disclosure of competing interests in ICMJE journals. N Engl J Med. 2009;361:1896-7.

12. Network European Society of Cardiology Task Force. Conflict of interest policies and disclosure requirements among European Society of Cardiology National Cardiovascular Journals. Eur Heart J. 2012;33:587-94.

13. Davidoff F, DeAngelis CD, Drazen JM, et al. Sponsorship, authorship, and accountability. N Engl J Med. 2001;345:825-6.

14. Taichman DB, Backus J, Baethge C, et al. Sharing clinical trial data - a proposal from the international committee of medical journal editors. N Engl J Med. 2016;374:384-6.

15. Merson L, Gaye O, Guerin PJ. Avoiding data dumpsters - toward equitable and useful data sharing. N Engl J Med. 2016;374:2414-5.

16. Krumholz HM, Waldstreicher J. The Yale Open Data Access (YODA) project - a mechanism for data sharing. N Engl J Med. 2016;375:403-5.

17. Loder E, Groves T. The BMJ requires data sharing on request for all trials. BMJ. 2015;350:h2373. doi:10.1136/bmj.h2373.

18. Kavsak PA. The International Committee of Medical Journal Editors proposal for sharing clinical trial data and the possible implications for the peer review process. Ann Transl Med. 2016;4:115.

19. Manamley N, Mallett S, Sydes MR, et al. Data sharing and the evolving role of statisticians. BMC Med Res Methodol. 2016;16(Suppl 1):75.

20. Institute of Medicine. Sharing clinical trial data: maximizing benefits, minimizing risk. Washington, DC: The National Academies Press; 2015.

21. Vallance P, Freeman A, Stewart M. Data sharing as part of the normal scientific process: a view from the pharmaceutical industry. Plos Med. 2016;13:e1001936.

22. World Health Organisation. www.who.int/ictrp/results/WHO_ Statement_results_reporting_clinical_trials.pdf?ua $=1$. 
23. Modjarrad K, Moorthy VS, Millet P, Gsell P-S, Roth C, Kieny M-P. Developing global norms for sharing data and results during public health emergencies. Plos Med. 2015;13:e1001935.

24. Coady SA, Wagner E. Sharing individual level data from observational studies and clinical trials: a perspective from NHLBI. Trials. 2013;14:201.

25. Geifman N, Bollyky J, Bhattacharya S, Butte AJ. Opening clinical trial data: are the voluntary data-sharing portals enough? BMC Med. 2015;13:280.

26. Van Tuyl S, Whitmire AL. Water, water, everywhere: defining and assessing data sharing in academia. PLOS ONE. 2016;11:e0147942.

27. Sudlow R, Branson J, Friede T, Morgan D, Whately-Smith C. EFSPI/PSI working group on data sharing: accessing and working with pharmaceutical clinical trial patient level datasets - a primer for academic researchers. BMC Med Res Methodol. 2016;16(Suppl 1):73.

28. Drazen JM. Data sharing and the journal. N Engl J Med. 2016; 374:e24. doi:10.1056/NEJMe1601087.

29. Hopkins C, Sydes M, Murray G, et al. UK publicly funded clinical trials units supported a controlled access approach to share individual participant data but highlighted concerns. J Clin Epidemiol. 2016;70:17-25.

30. Lo B. Sharing clinical trial data: maximizing benefits, minimizing risk. JAMA. 2015;313:793-4.

31. Ross JS, Krumholz HM. Open access platforms for sharing clinical trial data. JAMA. 2016;316:666.
32. Academic Research Organization Consortium for Continuing Evaluation of Scientific Studies - Cardiovascular (ACCESS CV). Sharing data from cardiovascular clinical trials - a proposal. N Engl J Med. 2016;375:407-9.

33. Fletcher C, Hollis S, Burger HU, Gerlinger C. Statistical guidance for responsible data sharing: an overview. BMC Med Res Methodol. 2016;16(Suppl 1):74.

34. Tucker K, Branson J, Dilleen M, et al. Protecting patient privacy when sharing patient-level data from clinical trials. BMC Med Res Methodol. 2016;16(Suppl 1):77.

35. International Consortium of Investigators for Fairness in Trial Data Sharing, Devereaux PJ, Guyatt G, Gerstein H, Connolly S, Yusuf S. Toward fairness in data sharing. N Engl J Med. 2016;375:405-7.

36. Hayes R, Ayles H, Binka F, et al. Sharing clinical trial data. Lancet. 2016;387:2287.

37. Strom BL, Buyse M, Hughes J, Knoppers BM. Data sharing, year 1 - access to data from industry-sponsored clinical trials. N Engl $\mathrm{J}$ Med. 2014;371:2052-4.

38. Navar AM, Pencina MJ, Rymer JA, Louzao DM, Peterson ED. Use of open access platforms for clinical trial data. JAMA. 2016;315:1283-4.

39. Gonçalves LM, Seabra-Gomes R. Celebrating the 10th anniversary of the portuguese cardiology data collection center: a reflexion on its past, present, and future. Rev Port Cardiol. 2012;31:763-8.

40. Horton R. Offline: data sharing why editors may have got it wrong. Lancet. 2016;388:1143. 